\title{
CONCEPTS
}

\section{Mohave Rattlesnake (Crotalus scutulatus) Identification Revisited}

\author{
Michael D. Cardwell, MS ${ }^{1,2}$; Daniel J. Massey, PharmD ${ }^{1,3}$; Geoffrey Smelski, PharmD, DABAT ${ }^{1}$; \\ Wolfgang Wüster, $\mathrm{PhD}^{4,5}$ \\ ${ }^{1}$ Arizona Poison and Drug Information Center, Tucson, Arizona $;{ }^{2}$ Biology Department, San Diego State University, San Diego, California; ${ }^{3}$ Banner \\ University Medical Center, Tucson, Arizona; ${ }^{4}$ Molecular Ecology and Evolution at Bangor, School of Natural Sciences, Bangor University, Bangor, \\ United Kingdom; ${ }^{5}$ Chiricahua Desert Museum, Rodeo, New Mexico
}

\begin{abstract}
Crotalus scutulatus (Mohave rattlesnake) is a clinically significant pit viper broadly distributed across much of the arid southwestern United States and mainland Mexico. Identification of $C$ scutulatus is a concern among emergency medical service and emergency department personnel owing to its reputation for severe envenomations and difficulty in visually differentiating between $C$ scutulatus and other species, primarily Crotalus atrox (western diamond-backed rattlesnake). We contrast distinctive characteristics of C scutulatus, $C$ atrox, and 3 other sympatric species: Crotalus molossus, Crotalus ornatus, and Crotalus viridis (western and eastern black-tailed rattlesnakes and prairie rattlesnake, respectively). Greenish coloration eliminates $C$ atrox but does not confirm $C$ scutulatus. Obvious coarse and fine speckling of the dorsal pattern and a pale postocular stripe intersecting the mouth characterize $C$ atrox. Dorsal speckling is insignificant or absent in the other species, whereas the pale postocular stripe passes above the mouth in $\mathrm{Cscu}$ tulatus and $C$ viridis and is absent in $C$ molossus and $C$ ornatus. Tails boldly ringed with alternating black and white or contrasting shades of gray are shared by $C$ atrox and $C$ scutulatus, respectively, but a lack of boldly ringed tails characterizes the other species. The proximal rattle segment is yellow and black, or entirely yellow, in $C$ scutulatus but black in the others. The most reliable visual identifications are based on evaluations of multiple traits, all of which are variable to some extent. Traits such as tail ring width and the size and number of crown scales have frequently been overemphasized in the past.
\end{abstract}

Keywords: Mojave rattlesnake, Mojave green, snakebite, rattlesnake identification

\section{Introduction}

Over the 2 decades since one of us coauthored "Mojave rattlesnake (Crotalus scutulatus scutulatus) identification," it has become apparent that distinguishing $C$ scutulatus (Mohave rattlesnake ${ }^{2}$ ), particularly from sympatric Crotalus atrox (western diamond-backed rattlesnake), is more complex than originally thought. After little initial interest in the original paper, it has attracted considerable

Corresponding author: Michael D. Cardwell, MS, Arizona Poison and Drug Information Center, Department of Biological Sciences, San Diego State University, 5201 W Via Mallorca, Tucson, AZ 85745-9461; e-mail: mikecardwell31@gmail.com.

Submitted for publication October 2021.

Accepted for publication January 2022.

(C) 2022 Wilderness Medical Society. Published by Elsevier Inc. This is an open access article under the CC BY-NC-ND license (http:// creativecommons.org/licenses/by-nc-nd/4.0/).

https://doi.org/10.1016/j.wem.2022.01.003 recent attention, accumulating $>900$ reads on researchgate. net since 2014 and recently adding approximately 12 reads per week. Two additional decades of research combined with the aforementioned interest argue for an updated and expanded treatment of the subject. Herein, we explain that there is no single observable trait that will reliably identify $C$ scutulatus or differentiate the species from others. Consequently, the most reliable visual identifications are based on evaluation of multiple traits, all of which are variable to some extent.

C scutulatus is distributed across much of the arid southwestern United States and deep into mainland Mexico, and its range overlaps largely with $C$ atrox (Figure 1). C scutulatus is well known for venom that contains a presynaptic PLA $_{2}$ neurotoxin named Mojave toxin. ${ }^{3}$ Yet in a large area of south-central Arizona (as well as some parts of Mexico), $C$ scutulatus produces venom that lacks Mojave toxin but contains 


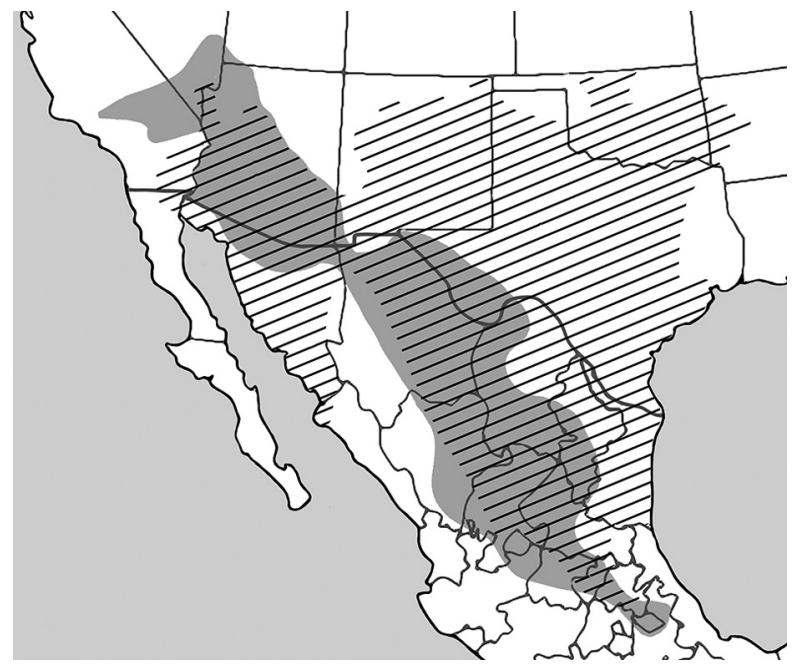

Figure 1. Distribution of Crotalus scutulatus (shaded area) and of Crotalus atrox (cross-hatched area).

tissue-destroying and hemorrhagic snake venom metalloproteinases (SVMPs) and other biologically active proteins and peptides, like $C$ atrox and many other pitvipers. $^{4-7}$

Extensive gene flow has been demonstrated between adjacent Arizona populations of $C$ scutulatus with neurotoxic venom (venom- $\mathrm{A}^{4}$ and type $\mathrm{II}^{8}$ ) and those without neurotoxin but rich in SVMPs (venom- ${ }^{4}$ and type $\mathrm{I}^{8}$ ), yet neither venom type appears to be spreading into the other population. ${ }^{7}$ The poorly defined intergrade zone contains some animals that express both Mojave toxin and SVMPs, termed venom-A+B. ${ }^{6,7,9}$

Venomous snakes produce an average of about 6 annual fatalities in the United States, many of which occur outside the range of $C$ scutulatus, ${ }^{10}$ yet the species has a widespread but undeserved reputation for being especially deadly despite dozens of annual bites that rarely produce fatalities. ${ }^{11}$ Anecdotal, misquoted, and sometimes fabricated accounts of $C$ scutulatus hybrids are common in social media, on the Internet, and occasionally in the mainstream news media. ${ }^{11}$ Yet despite decades of searching for wild hybrid rattlesnakes by multiple investigators, some looking for genetic evidence, only 1 small population of wild hybrids involving $C$ scutulatus has been found: a well-established population of $C$ scutulatus $\mathrm{x}$ viridis (Mohave $\mathrm{x}$ prairie rattlesnake) hybrids in Hidalgo County, New Mexico. ${ }^{12}$ Like the intermediate venom- $\mathrm{A}+\mathrm{B}$ animals in Arizona, most Hidalgo County hybrids express both Mojave toxin and SVMPs in their venom. Yet many of the traits previously suspected of indicating hybrids elsewhere have been shown by repeated investigations to be variations in unhybridized animals. $^{12-14}$
We provide an updated assessment of how various traits compare between $C$ scutulatus and $C$ atrox. Additionally, we include distinguishing features of 3 other species that are occasionally, but less frequently, misidentified as $C$ scutulatus: Crotalus molossus (western black-tailed rattlesnake) and Crotalus ornatus (eastern black-tailed rattlesnake), which are broadly sympatric with $C$ scutulatus in Arizona, New Mexico, and Texas; and Crotalus viridis (prairie rattlesnake), which is sympatric with $C$ scutulatus in New Mexico and Texas (summarized in Table 1). Note, however, that our identification guidelines are confined to United States populations. Some Mexican populations, especially of $C$ scutulatus and $C$ molossus, differ substantially from their US conspecifics, especially in color and pattern.

\section{Safety Concerns}

Live rattlesnakes can strike nearly their entire length. Dead rattlesnakes and even severed heads may reflexively bite and envenomate if handled even several hours after death. ${ }^{15-17}$ Some snakebite patients or their companions occasionally bring the snake that delivered the bite to the emergency department. Live rattlesnakes should generally not be allowed into ambulances or clinics. Opening a container holding a live rattlesnake is extraordinarily dangerous. Apparently dead rattlesnakes should be manipulated with tools longer than the snake, and severed heads should never be manipulated by hand, even with gloves.

Countless references, both popular and scholarly, describe identifying characteristics that often include fine-scale traits that cannot be examined safely on a live rattlesnake. We have divided our comments into gross traits that can be observed and photographed from a safe distance ( $\geq$ twice the length of the snake) and fine-scale traits that can be used when examining a dead snake, a high-quality photograph, or occasionally a live animal secured in a transparent glass or plastic container. In the latter case, care must be taken to avoid allowing fingers or other body parts to touch air holes and other places where a fang might protrude if the snake inside strikes. Attempting to put a live rattlesnake into a transparent container to facilitate close examination should never be considered.

\section{Gross Identifying Characteristics}

The tail of nearly all rattlesnakes terminates in a hard keratinous "rattle." Baby rattlesnakes have a single hard button, like the eraser on a pencil. Older rattlesnakes have segmented rattles of varying lengths. Rattlesnakes with 
deformed or missing rattles, caused by either genetic deformity or trauma, are encountered on rare occasions. Invariably, such deformed rattlesnakes have a blunt stub for a tail, with or without a deformed rattle. Even the socalled "rattleless" rattlesnake, Crotalus catalinensis, has a single rattle segment on a blunt tail. Thus, regardless of potentially atypical color or markings, no sympatric rattlesnake has a tapered pointed tail.

C scutulatus is a heavy-bodied snake, with typical adults averaging about 60 to $90 \mathrm{~cm}$ in length with a single row of large, roughly diamond-shaped blotches along the dorsal midline, an unmarked white or pale-yellow ventral surface, and alternating dark and pale rings on the tail. The greatest verified length is $124 \mathrm{~cm}$. Neonates are perfect miniatures of the adults, averaging about $29 \mathrm{~cm}$ long. ${ }^{11,14} C$ atrox looks broadly similar, and most adults are similar in size to $C$ scutulatus, although $C$ atrox can be much larger (largest recorded $=226 \mathrm{~cm}) .{ }^{18} \mathrm{C}$ molossus and $C$ ornatus are similar to $C$ scutulatus in size and body shape, but with high-contrast dark dorsal blotches that are less diamond-shaped compared to $C$ scutulatus and $C$ atrox. ${ }^{19} C$ viridis is similar in appearance but with more rounded dorsal blotches that are more widely spaced. ${ }^{20}$

\section{DORSAL COLOR AND MARKINGS}

The dorsal color of $C$ scutulatus sometimes features a greenish tinge, although some animals are shades of brown, tan, gray, or even yellowish, with little or no green. The dorsal blotches typically consist of dark centers, surrounded by a single row of darker scales, with an outer margin of pale scales, all on a medium-toned background. Significantly, there is little speckling within the dorsal blotches and the colored margins are well defined, resulting in a crisp, clean pattern. The monochrome light and dark scales of the blotch edges usually give the blotches a characteristically serrated outline (Figure 2A).

The dorsal color of $C$ atrox is typically a mixture of brown, tan, or gray, often blending into an orange or salmon tint near the tail. In some animals, the entire body has an orange/pink tint. Significantly, however, the authors know of no $C$ atrox with a greenish dorsal color. The shape of the dorsal blotches is less well defined than in $C$ scutulatus. Dark scales occur within the blotches, making the inner dark margins poorly demarcated. Some scales of the posterior portion of the pale outer margins are usually partially or entirely white (Figure 2B), unlike C scutulatus. Overall, the impression is often of a rather faded, washed-out pattern.

$C$ molossus and $C$ ornatus are highly variable, with background colors ranging from gray to greenish, brown, or bright yellow, with darker dorsal blotches that seldom 

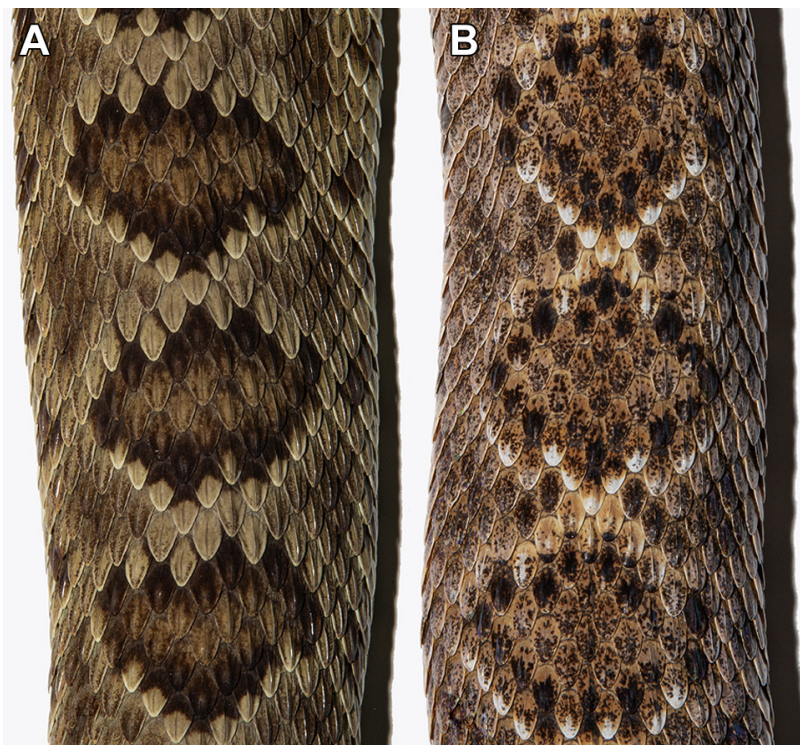

Figure 2. Typical dorsal colors and markings of most Crotalus scutulatus (A) and Crotalus atrox (B). Top is cranial. Although colors of individuals of both species may be darker or paler and some $C$ scutulatus are not greenish, $C$ atrox may be many shades of gray, brown, and pink, but not greenish, posterior margins of diamonds are edged in white, and the pattern is notably more speckled with poorly defined margins.

touch or overlap and tend to be elongated laterally. The blotches consist of a dark outline with a center of the same color as the background, and at least those on the
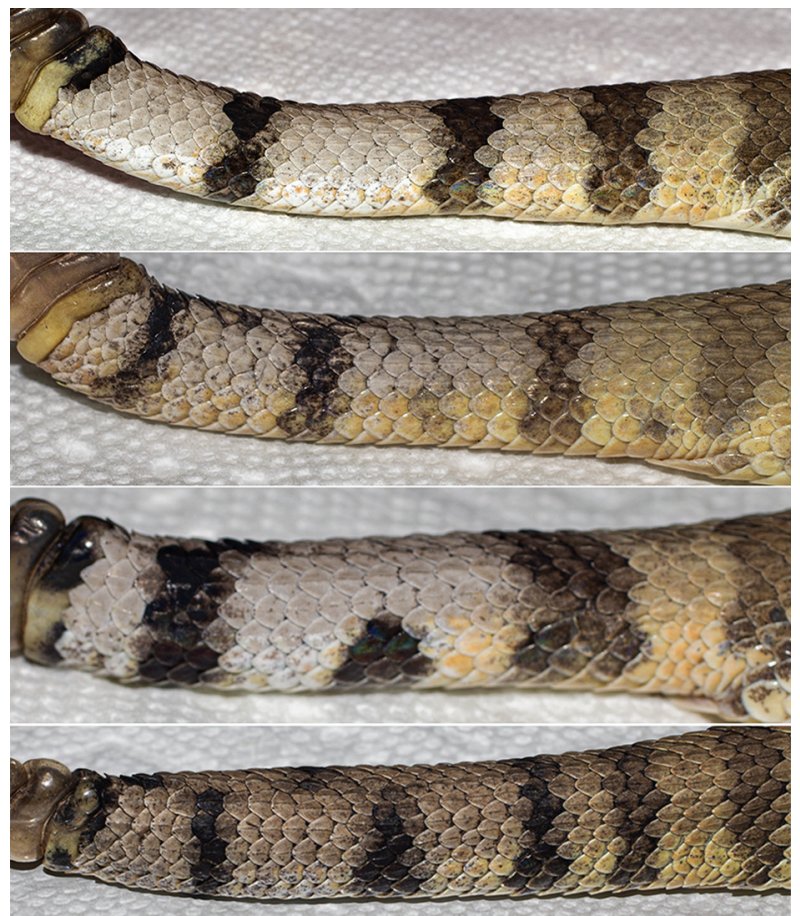

Figure 3. Selection of typical caudal markings of Crotalus scutulatus. caudal two-thirds of the body extend laterally toward the ventral surface via narrow dark zigzag bars. The blotches may have light outer edges, but these are often
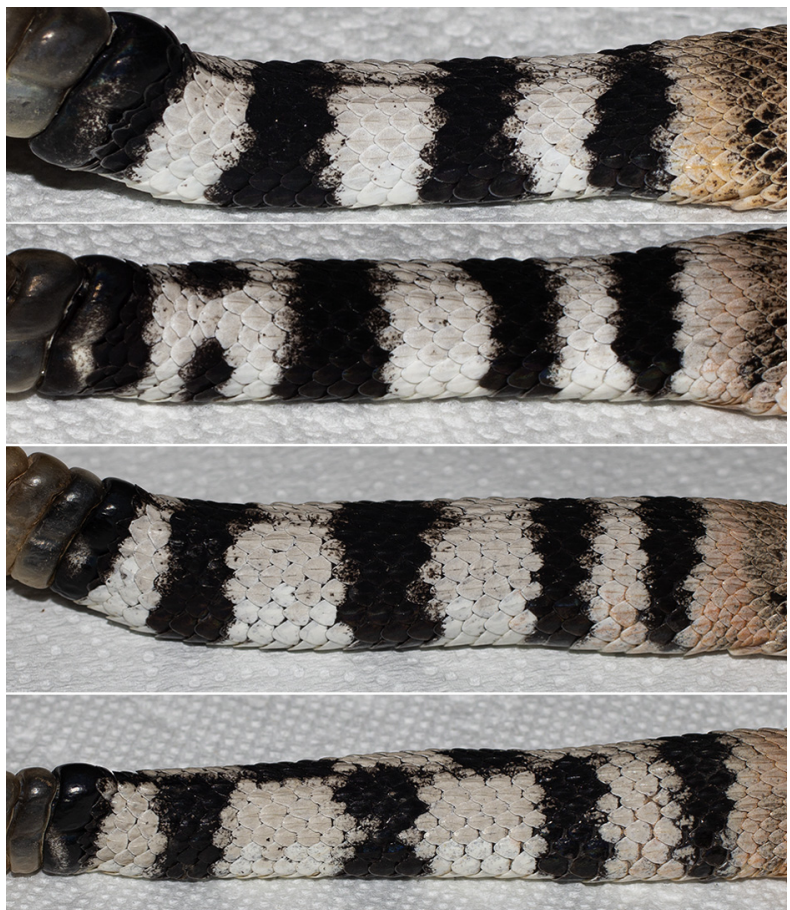

Figure 4. Selection of typical caudal markings of Crotalus atrox. 

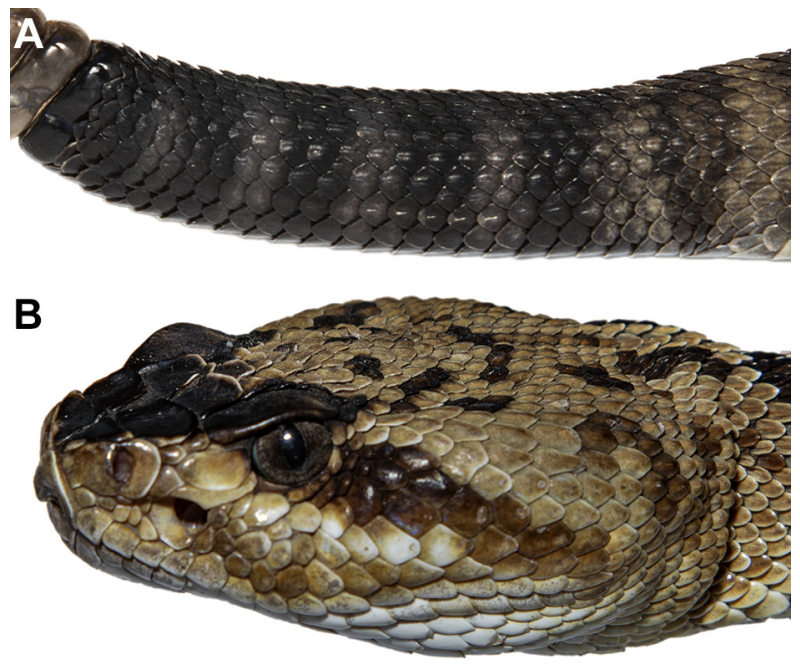

Figure 5. Crotalus molossus, showing faint pale caudal rings found on some animals (A) and lack of a pale postocular stripe (B). Both traits also apply to Crotalus ornatus.

poorly defined. Individual scales are usually monochrome, giving a serrated or pixelated outline to all pattern elements. The dorsal color of $C$ viridis is usually dominated by olive green and/or brown, with rather oval or hexagonal dark dorsal blotches, usually with a thin pale outline. Greenish specimens of all 3 species are sometimes confused with $C$ scutulatus owing to the mistaken belief that any greenish rattlesnake must be $C$ scutulatus, stemming from the common moniker "Mohave green rattlesnake."
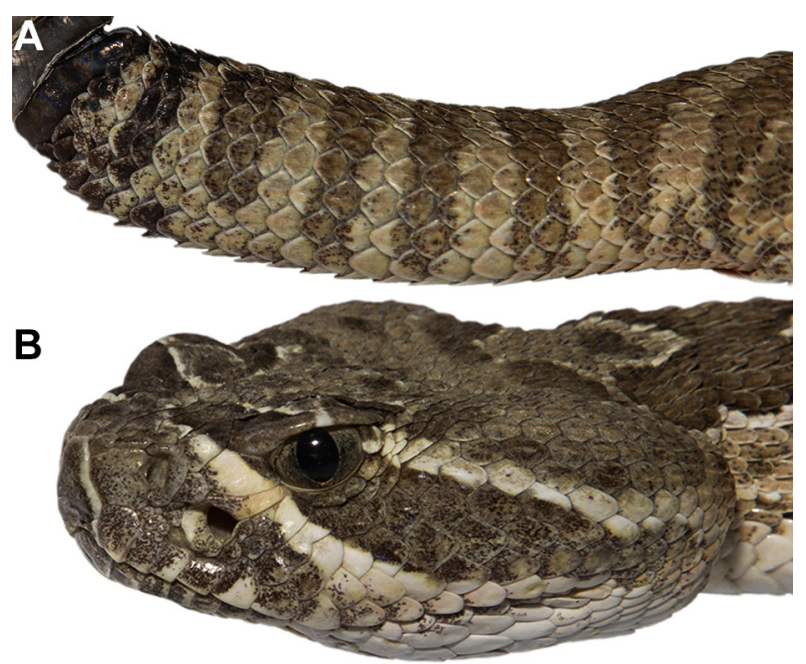

Figure 6. Crotalus viridis, showing narrow caudal rings of the same colors as the body (A) and the distinct pale postocular stripe (B) passing above the corner of the mouth.

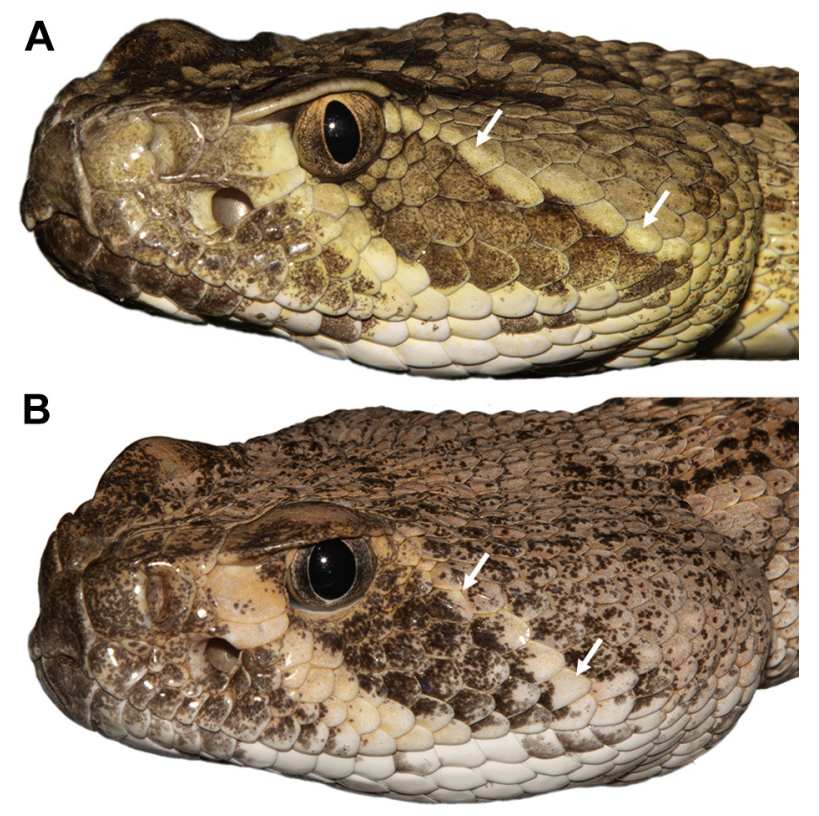

Figure 7. Facial markings of Crotalus scutulatus (A) and Crotalus atrox (B). Note that the postocular pale stripe (arrows) passes above the corner of the mouth in $C$ scutulatus but intersects the mouth in $C$ atrox.

Nonetheless, variations in pattern can complicate identification. Distorted, merged, and fragmented dorsal blotches are common in the nuchal area of all 5 species and, occasionally, elsewhere on the animals. Some of these variations occur regionally but are outside the scope of this account. On extraordinarily rare occasions, striped, patternless, and leucistic individuals have been encountered.

\section{CAUDAL COLOR AND MARKINGS}

The width of alternating dark and pale caudal rings is commonly suggested to distinguish between $C$ scutulatus and $C$ atrox, yet this trait is quite variable. Although popularly described as "rings," these markings frequently do not extend across the ventral surface of the tail in both species. Furthermore, the dark rings are often fragmented, incomplete, and sometimes offset at the dorsal midline. In $C$ scutulatus, the pale color on the tail may be various shades of gray but is occasionally nearly white or even tan. The dark rings may be black, dark gray, or brownish and are usually considerably narrower than the pale spaces between them, but their number, spacing, and width are highly variable (Figure 3 ).

Caudal rings in $C$ atrox usually consist of a bright white background and pure black rings, often about as wide as the white spaces between them. However, the 


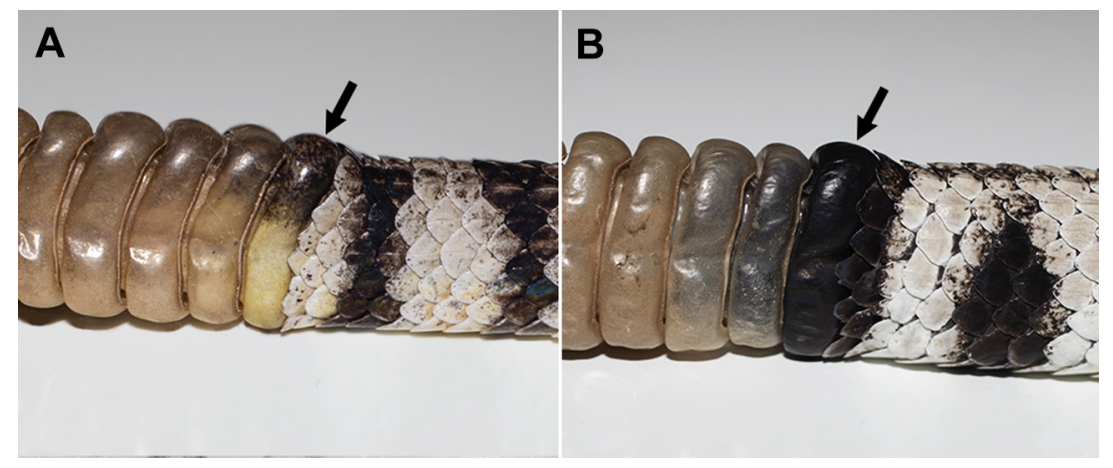

Figure 8. Live tissue is visible within the proximal rattle segment (arrows). Proximal rattle segment is light yellow or bicolor (yellow and black) in Crotalus scutulatus (A) but usually entirely black in Crotalus atrox (B).

shape and spacing of the black markings are inconsistent (Figure 4).

As their common names suggest, $C$ molossus and $C$ ornatus have uniformly black, brown, or dark smokey gray tails, sometimes with faint narrow pale rings (Figure 5A), especially in juveniles. The overall impression is invariably of a dark, relatively uniform tail. The dark tail alone separates them unmistakably from $C$ atrox and $C$ scutulatus. The tail of $C$ viridis bears narrow alternating rings of the same colors as the dorsal body, with the dark body blotches morphing into dark caudal rings separated by background body color (Figure 6A).

\section{FACIAL MARKINGS}

Both $C$ scutulatus and $C$ atrox bear 2 pale facial stripes bilaterally, one originating just anterior to the eye and the other just posterior, termed preocular and postocular stripes, respectively. Both stripes sweep down and extend caudally. The postocular stripe passes above the corner of the mouth and sometimes extends horizontally beyond the mandibles in C scutulatus (Figure 7A) but drops down and intersects the mouth in $C$ atrox (Figure 7B). However, it is not uncommon in both species for the postocular stripe to pass very close to or contact the corner of the mouth, which is complicated by the exact extent of the closed mouth being difficult to discern from a safe distance.

An indistinct pale preocular stripe may be visible on $C$ molossus and $C$ ornatus, but these species lack the pale postocular stripe (Figure 5B). C viridis bears a pale postocular stripe (Figure 6B) similar to that of $C$ scutulatus, rendering the trait useless in differentiating between them.

\section{COLOR OF PROXIMAL RATTLE SEGMENT}

The newest rattle segment is found at the base of the rattle and contains live tissue. The color of the live tissue in the proximal segment is visible and usually bicolor (pale yellow and black) or entirely pale yellow in $C$ scutulatus (Figures 3 and 8A). In adult or sub-adult $C$ atrox, the proximal segment is entirely black, sometimes with a faint superficial brush of white (Figures 4 and $8 \mathrm{~B}$ ). However, the proximal segment of neonates and juveniles of $C$ atrox (1-3 rattle segments) are pale, sometimes

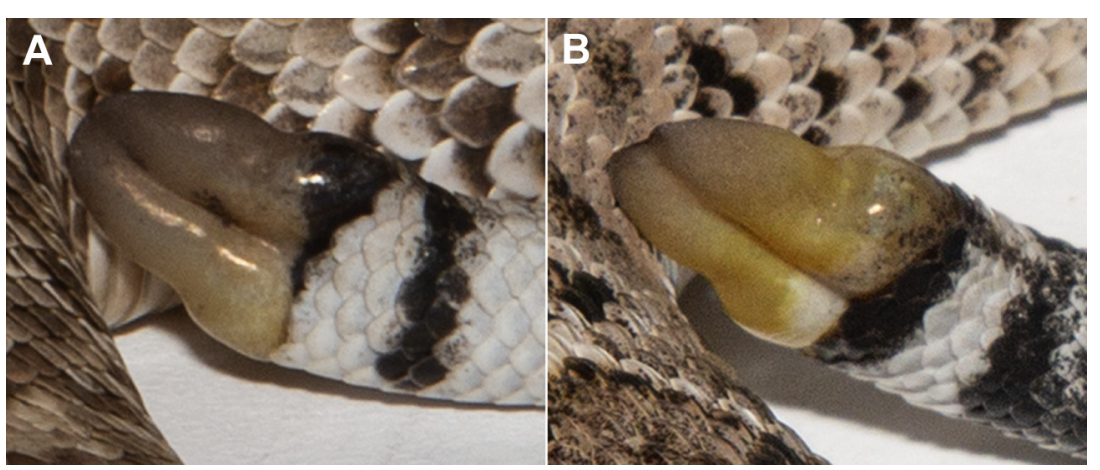

Figure 9. First rattle segments of neonate Crotalus scutulatus (A) and Crotalus atrox (B). 


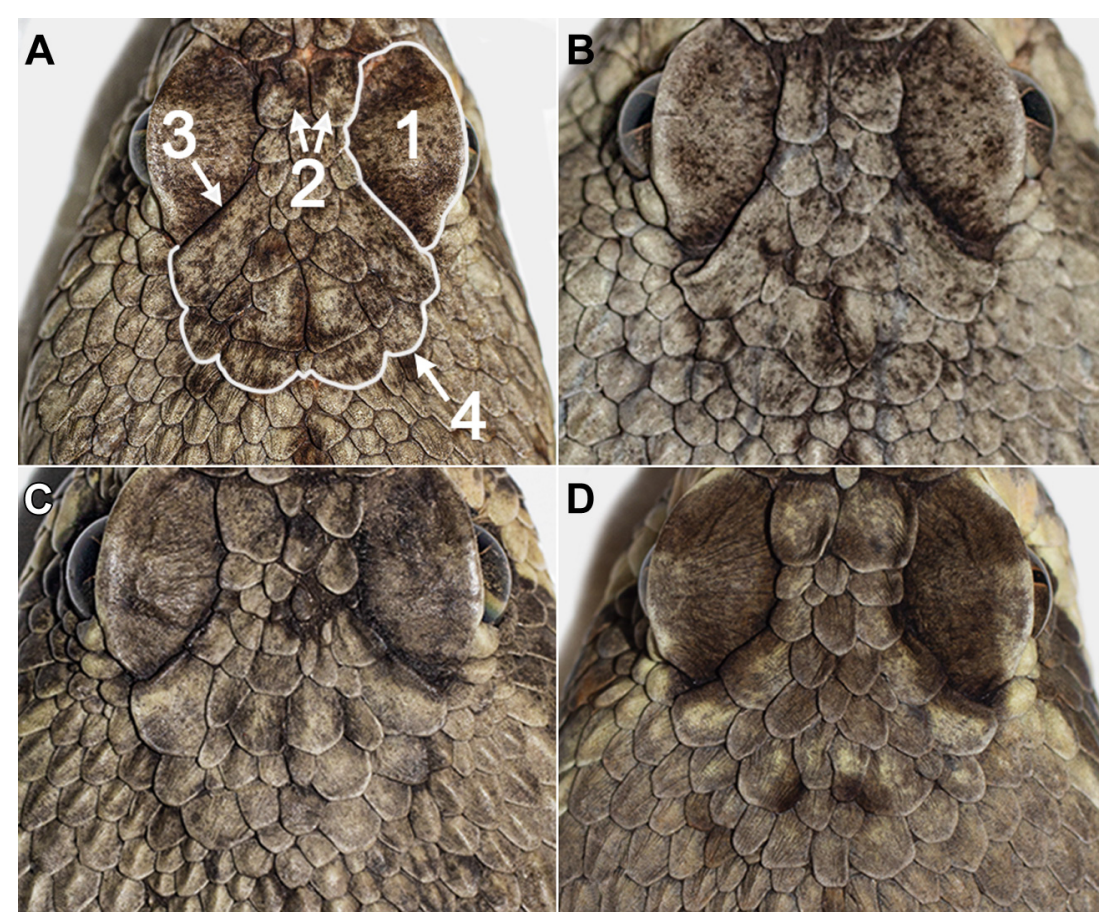

Figure 10. Crown scales on Crotalus scutulatus are highly variable in size, shape, number, and arrangement. Terminology (A): right supraocular scale (1), fewest crown scales separating supraoculars (2), deep furrow where enlarged crown scales overlay the supraocular (3), and posterior margin of enlarged crown scales (4). Two scales separating supraoculars (B). Three scales separating supraoculars (C). Enlarged crown scales more evenly shaped, sized, and blended than usual (D).

yellowish or reddish (Figure 9B). C molossus, C ornatus, and $C$ viridis have black proximal rattle segments (Figures 5A and 6A).

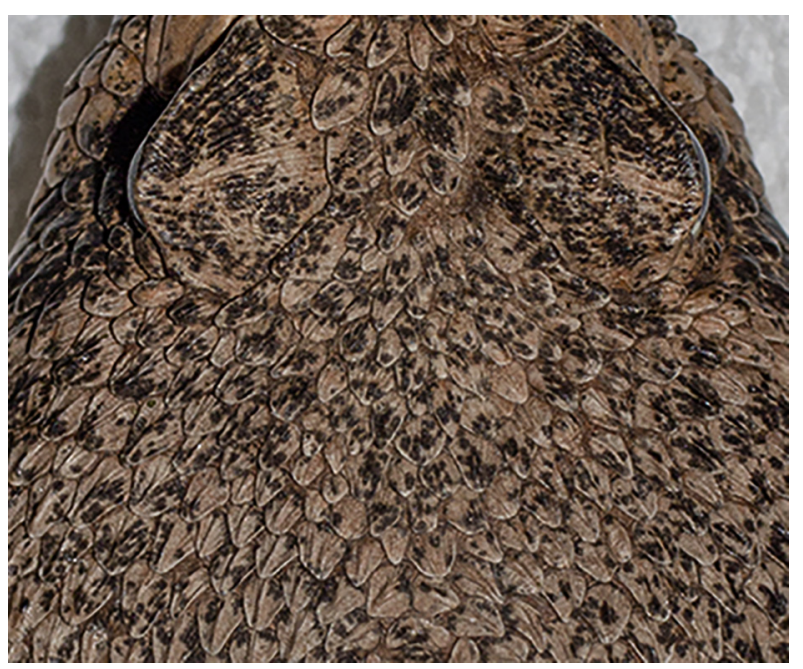

Figure 11. Typical crown scales of Crotalus atrox. Although there are often a few irregularly sized and shaped scales, especially anteriorly, most crown scales are small and similar in size and shape to scales on the parietal region. Note the distinct dark speckling on the scales compared to Crotalus scutulatus (Fig. 10).

\section{Fine-Scale Identifying Characteristics}

Do not attempt examination on a live rattlesnake.

\section{CROWN SCUTELLATION}

Two large crown scales separating the supraocular scales are commonly listed as diagnostic for $C$ scutulatus, yet the supraoculars are separated by 3 and occasionally 4 scales in about $14 \%$ of individuals ${ }^{14}$ (Figure 10). The crown scales of $C$ atrox and $C$ viridis are more granular, with at least 4 and usually many more scales separating the supraoculars (Figure 11).

Although the small scales between the supraoculars of $C$ atrox and $C$ viridis merge relatively seamlessly with similar scales in the parietal region, the enlarged crown scales of $C$ scutulatus are irregular in shape and size and fan out onto the parietal region of the head. Additionally, in $C$ scutulatus, the medial edges of the supraoculars tuck under the enlarged crown scales, forming a deep, dark furrow (Figure 10) that is missing in most or all $C$ atrox (Figure 11) and $C$ viridis.

$C$ molossus and $C$ ornatus have a series of large, squarish scales on the crown forward of the eyes and the supraoculars are separated by 2 large scales 
nearest the rostrum, but they lack the "fan" of enlarged crown scales extending onto the parietal region.

\section{FINE SPECKLING ON SCALES}

Many dorsal scales on $C$ atrox are multicolored, with most bearing many dark speckles of varying sizes. Dorsal scales on $C$ scutulatus, as well as $C$ molossus and $C$ ornatus, are generally monochromatic with little or no speckling. In $C$ viridis, some features like the pale outlines of dorsal blotches cut across individual scales.

\section{Conclusions}

Determining whether a particular rattlesnake is $C$ scutulatus or $C$ atrox can be challenging, with distinction from $C$ molossus, $C$ ornatus, and $C$ viridis being somewhat less so. All identifying traits are variable, and some highly so. Despite ample rumors, wild hybrid rattlesnakes are very rare, with variation in identifying characters being common in genetically pure animals of all species. On extraordinarily rare occasions, aberrant individuals of each species have been encountered, including striped, patternless, and leucistic animals, ${ }^{11,14}$ but no sympatric rattlesnake has a tapered pointed tail.

In general, $C$ scutulatus sometimes displays a greenish tinge, its dorsal pattern is well defined with little or no speckling, the pale postocular facial stripe sweeps rearward and usually does not intersect the mouth, caudal rings tend to be alternating shades of pale gray with narrower dark gray, and the proximal rattle segment is partially or entirely pale yellow.

$C$ atrox is not greenish in color, margins in the dorsal pattern appear ragged or washed out with heavy speckling, the pale postocular facial stripe intersects the mouth, caudal rings are usually high-contrast black and white, and the proximal rattle segment is usually entirely black (in all but very small animals) with an occasional faint brush of white.

$C$ molossus and $C$ ornatus have uniformly dark tails, sometimes with faint narrow pale rings, and black proximal rattle segments. $C$ viridis has widely separated ovoid dorsal blotches, tails ringed in the same colors as the dorsum, and black proximal rattle segments.

Although determining which species is involved can be helpful in evaluating the potential clinical course of an envenomation, specific identification is not necessary for antivenom selection, and clinicians must remain alert and prepared for unexpected sequelae. Attempting to identify a live rattlesnake is potentially dangerous, and the risk almost always outweighs any perceived benefit. Wellfocused digital photographs taken by the patient or bystanders and transmitted to a poison control center can often be quickly identified by a consulting herpetologist.

Author Contributions: Study concept and design (MDC); data acquisition (MDC, DJM, WW); data analysis and interpretation, drafting and critical revision the manuscript; approval of the final manuscript (MDC, DJM, GS, WW).

Financial/Material Support: None.

Disclosures: None.

\section{References}

1. Bush SP, Cardwell MD. Mojave rattlesnake (Crotalus scutulatus scutulatus) identification. Wilderness Environ Med. 1999;10(1):6-9.

2. Crother BI, Bonett RM, Boundy J, Burbrink FT, de Queiroz K, Frost DR, et al. Scientific and Standard English Names of Amphibians and Reptiles of North America North of Mexico, with Comments Regarding Confidence in our Understanding. 8th ed. Society for the Study of Amphibians and Reptiles, Herpetological Circular \#43; 2017:64-5.

3. Bieber AL, Tu T, Tu AT. Studies of an acidic cardiotoxin isolated from the venom of Mojave rattlesnake (Crotalus scutulatus). Biochim Biophys Acta. 1975;400(1):178-88.

4. Glenn JL, Straight R. Mojave rattlesnake Crotalus scutulatus scutulatus venom: variation in toxicity with geographical origin. Toxicon. 1978;16(1):81-4.

5. Calvete JJ, Fasoli E, Sanz L, Boschetti E, Righetti PG. Exploring the venom proteome of the western diamondback rattlesnake, Crotalus atrox, via snake venomics and combinatorial peptide ligand library approaches. J Proteome Res. 2009;8(6):3055-67.

6. Massey DJ, Calvete JJ, Sanchez EE, Sanz L, Richards K, Curtis R, et al. Venom variability and envenoming severity outcomes of the Crotalus scutulatus scutulatus (Mojave rattlesnake) from southern Arizona. J Proteomics. 2012;75(9):2576-87.

7. Zancolli G, Calvete JJ, Cardwell MD, Greene HW, Hayes WK, Hegarty MJ, et al. When one phenotype is not enough: divergent evolutionary trajectories govern venom variation in a widespread rattlesnake species. Proc Biol Sci. 2019;286(1898):20182735.

8. Mackessy SP. Venom composition in rattlesnakes: Trends and biological significance. In: Hayes WK, Beaman KR, Cardwell MD, Bush SP, eds. The Biology of Rattlesnakes. Loma Linda, CA: Loma Linda Univ Press; 2008:495-510.

9. Wilkinson JA, Glenn JL, Straight RC, Sites Jr JW. Distribution and genetic variation in venom A and B populations of the Mojave rattlesnake (Crotalus scutulatus scutulatus) in Arizona. Herpetologica. 1991;47(1):54-68.

10. Forrester JA, Weiser TG, Forrester JD. An update on fatalities due to venomous and nonvenomous animals in the United States (2008-2015). Wilderness Environ Med. 2018;29(1):36-44.

11. Cardwell MD. The Mohave Rattlesnake and How It Became an Urban Legend. Rodeo, New Mexico: ECO Publishing; 2020.

12. Zancolli G, Baker TG, Barlow A, Bradley RK, Calvete JJ, Carter $\mathrm{KC}$, et al. Is hybridization a source of adaptive venom variation in rattlesnakes? A test, using a Crotalus scutulatus $\mathrm{x}$ viridis hybrid zone in southwestern New Mexico. Toxins (Basel). 2016;8(6):188.

13. Jacob JS. An evaluation of the possibility of hybridization between the rattlesnakes Crotalus atrox and C. scutulatus in the southwestern United States. Southwest Nat. 1977;22(4):469-85.

14. Cardwell MD. Species accounts. Mohave rattlesnake (Crotalus scutulatus). In: Schuett GW, Feldner MJ, Smith CF, Reiserer RS, 
eds. Rattlesnakes of Arizona. vol. 1. Rodeo, New Mexico: ECO Publishing; 2016:563-605.

15. Klauber LM. Experiments with decapitated rattlesnakes. In: Klauber LM. Rattlesnakes: Their Habits, Life Histories, and Influence on Mankind. Berkeley and Los Angeles, California: Univ Calif Press; 1956:310-4. [2 $2^{\text {nd }}$ ed. 1997:342-6]

16. Emswiler MP, Griffith FP, Cumpston KL. Clinically significant envenomation from postmortem copperhead (Agkistrodon contortrix). Wilderness Environ Med. 2017;28(1):43-5.

17. Hinze JD, Barker JA, Jones TR, Winn RE. Life-threatening upper airway edema caused by a distal rattlesnake bite. Ann Emerg Med. 2001;38(1):79-82.
18. Schuett GW, Repp RA, Spencer CL, Beaman KR, Painter CW. Species accounts: Western diamond-backed rattlesnake (Crotalus atrox). In: Schuett GW, Feldner MJ, Smith CF, Reiserer RS, eds. Rattlesnakes of Arizona. vol. 1. Rodeo, New Mexico: ECO Publishing; 2016:333-94.

19. Persons TB, Feldner MJ, Repp RA. Species accounts: blacktailed rattlesnake (Crotalus molossus). In: Schuett GW, Feldner MJ, Smith CF, Reiserer RS, eds. Rattlesnakes of Arizona. vol. 1. Rodeo, New Mexico: ECO Publishing; 2016:461-505.

20. Davis MA, Douglas ME. Species accounts: prairie rattlesnake (Crotalus viridis). In: Schuett GW, Feldner MJ, Smith CF, Reiserer RS, eds. Rattlesnakes of Arizona. vol. 1. Rodeo, New Mexico: ECO Publishing; 2016:289-332. 